\title{
Undocumented Graduate Students in the US: Facing the Future in a Tumultuous Sociopolitical Context
}

\author{
Natalie Xiomara Aguilar \\ University of California, Los Angeles
}

\begin{abstract}
The United States has been at a political impasse in resolving its immigration dilemma for the last two and a half decades. Reaching a peak at over 43.7million immigrants residing in the U.S as of 2016, currently 10.7 million are unauthorized (Pew Research Center, 2018). The world has struggled for the last 5,000 years to provide individuals with the fundamental human right to learn, regardless of social or legal status, however, access to education has not reflected that. In fact, federal and institutional policies have been formulated to decrease access for minoritized groups. Undergraduates living with unauthorized status have recently been entering the college pathway and we are just beginning to learn about their experiences; we know less about their access and persistence through graduate education. Undocumented students are met with uncertainties related to career opportunities and job security, despite their educational pursuits and achievements, due to a tumultuous socio-political climate that present legal and institutional barriers. In spite of difficulties, there are students who choose to resiliently pursue advanced degrees. A qualitative, phenomenological approach was used to explore the lived experiences of 7 undocumented graduate students in California, as they transition into graduate education during a tumultuous socio-political state in the age of Donald Trump and the 2016 election. Inductive and deductive coding of semi-structured interviews resulted in findings that narrate the experiences of undocumented graduate students as they weave their way through the educational pipeline and American social fabric. Recommendations for institutions and higher education professionals are outlined.
\end{abstract}

Keywords: higher education; human rights; immigrant students; immigration policy; qualitative 